\title{
Hypoglycaemic, antioxidative and phytochemical evaluation of Cornus mas varieties
}

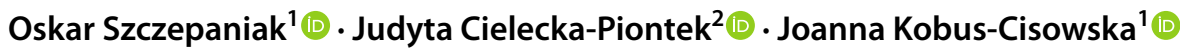

Received: 15 March 2020 / Revised: 13 September 2020 / Accepted: 19 September 2020

(c) The Author(s) 2020

\begin{abstract}
Cornelian cherry (Cornus mas L.) is a plant growing in Central and Eastern Europe. Its fruits are a rich source of anthocyanins, flavonoids and iridoids. Among the iridoids, loganic acid is the most prevalent. The study aimed to examine the relation between loganic acid content, antioxidant capacity and hypoglycaemic effect in vivo for three Polish cultivars of $C$. mas. All tested cultivars strongly inhibited $\alpha$-glucosidase and had similar amounts of highly bioabsorbable loganic acid. The loganic acid content was similar for each cultivar tested, while the cultivars differed in content of flavonoids and anthocyanins. The highest antioxidant potential was observed in the fruits of cv. Szafer, and the highest $\alpha$-glucosidase inhibitor was cv. P5. A statistical analysis has shown that hypoglycaemic properties are prevalently driven by anthocyanin content and the antioxidant capacity, especially ferric-reducing ability partially based on loganic acid.
\end{abstract}

Keywords Cornus mas $\cdot \alpha$-Glucosidase inhibitors $\cdot$ Loganic acid $\cdot$ Antioxidants

$\begin{array}{ll}\text { Abbreviations } \\ \text { ABTS } & \begin{array}{l}2,2^{\prime} \text {-Azino-bis(3-ethylbenzothiazoline-6-sul- } \\ \text { fonic acid) diammonium salt }\end{array} \\ \text { d.m. } & \text { Dry matter } \\ \text { FRAP } & \text { Ferric-reducing antioxidant capacity } \\ \text { GIT } & \text { Gastrointestinal tract cellular membranes } \\ \text { LA } & \text { Loganic acid } \\ \text { PAMPA } & \text { Parallel artificial membrane permeability assay } \\ \text { TAC } & \text { Total anthocyanin content } \\ \text { TEAC } & \text { Antiradical activity against ABTS radical } \\ \text { TFC } & \text { Total flavonoid content }\end{array}$

\section{Introduction}

The prevention of diseases of affluence seems to be the most important challenge for public health. The reason for the occurrence of this group of diseases, including overweight,

Oskar Szczepaniak

oskar.szczepaniak@up.poznan.pl

1 Department of Gastronomy Sciences and Functional Foods, Poznań University of Life Sciences, ul. Wojska Polskiego 28, 60-637 Poznan, Poland

2 Department of Pharmacognosy, Poznań University of Medical Sciences, ul. Święcickiego 4, 60-781 Poznan, Poland obesity, hypertension, atherosclerosis, osteoporosis, diabetes and neurodegenerative diseases, is an inappropriate lifestyle. Low levels of physical activity, smoking, excess stress, alcohol abuse and, above all, poor nutrition negatively impact the human body. In this context, oxidative stress and the methods of reducing it by looking for natural compounds that act as antioxidants are important issues $[1,2]$. The human body has several mechanisms to scavenge free radicals. They are based on the activity of enzymes such as superoxide dismutase, catalase and glutathione peroxidase. Antioxidants in food products, including fruits, vegetables, legumes, cereal grains, oilseeds, tea, herbs and spices, provide effective protection as well. The problem arises when there are more free radicals formed than the body can neutralize. Meanwhile, the body's defensive functions are compromised, which leads to oxidative stress. This, in turn, may initiate changes in the structure of nucleic acids, proteins, lipids and carbohydrates [3].

Over the last few years, the attention has been drawn to the nutritional benefits of cornelian cherry. The botanical family of Cornaceae includes approximately 40 species to be found in the moderate climate zone. The species that is cultivated, mainly for its useful fruits, is cornelian cherry (Cornus mas L.). Cornus mas is either a shrub or a small tree, which can grow even up $9 \mathrm{~m}$ in height [4]. In recent years, many researchers have paid particular attention to the fruits of cornelian cherry, describing their properties, 
not only those related to sensory characteristics and quality, but also the ones providing beneficial health effects. Cornelian cherry fruits are characterized by a high content of dry matter, roughly $85 \%$ of which are water-soluble compounds. The sour taste of C. mas fruits results from organic acids, such as malic and quinic acid. The main substances responsible for the biological activity of cornelian cherry are vitamin $\mathrm{C}$, anthocyanins, flavonoids and iridoids.

A particular group of active phytocompounds in C. mas is the iridoids, which is a large group of secondary metabolites occurring in many different plants, as well as in several animal species [5]. Loganic acid and its methyl derivative-loganin fall within the group of iridoid glycosides. Literature indicates that the key sources of loganic acid are fruit, including fruits of $C$. mas. In prior studies, an effect of individual iridoids was assayed and strong anti-inflammatory properties of loganic acid were observed. Loganic acid (administered topically in a form of eye drops) decreased intraocular pressure, which may be used in glaucoma treatment [6]. Moreover, the compound administered with diet may have a beneficial effect on lipid metabolism, which was observed as changes in triglyceride levels and HDL cholesterol fractions [7].

Iridoid compounds contained in cornelian cherry exhibit a multi-directional therapeutic effect, e.g. analgesic effect and protection against autoimmune disorders and inflammations [4]. What is more, loganin inhibits kidney damage induced by diabetes [8]. Selected iridoids or extracts containing these compounds were studied for their anti-inflammatory $[7,9,10]$ and antioxidant properties [11, 12].

However, iridoids have various pharmacological effects (including antibiotic, anti-inflammatory and hypotensive action) depending on their molecular structure [13]. Literature about $C$. mas fruits indicates that the content of individual iridoids in the plant is highly diverse. This diversification stems from the strong variability of cultivars and ecotypes of the plant. Moreover, Tenuta et al. [14] highlighted the fact that the antioxidant activity of iridoids is poorer than of flavonoids, which might be due to the differences in the number of hydroxyl groups between those two phytocompound groups. It was proven that the quantity of hydroxyl groups in a molecule positively relates to its antioxidant activity [15]. Although iridoids are predominant phytocompounds in cornelian cherry fruits, their antioxidant potential is noticeably high. The antioxidant potential can be driven by the synergic effect of all compounds present in the fruits.

Confirmed anti-inflammatory properties of loganic acid inspired us to validate the hypoglycaemic effect of cornelian cherry and determine the relationship between the activity and content of loganic acid in Corni fructus. Therefore, the key objective of this paper was to assess the inhibitory potential of selected cornelian cherry cultivars against $\alpha$-glucosidase.

\section{Materials and methods}

\section{Materials}

Three cultivars of C. mas L.-Szafer, Jolico and P5-were tested. Fruits of those cultivars were collected in September 2018 in the "Szynsad" orchard farm located in Dąbrówka Nowa, Błędów, Masovian Voivodeship, Poland (51 ${ }^{\circ} 47^{\prime} 01^{\prime \prime} \mathrm{N}$ $20^{\circ} 43^{\prime} 04^{\prime \prime} \mathrm{E}$ ). Cornelian cherries were collected in a production orchard where the fruit harvest time occurred in the third year of cultivation. Approximate $\mathrm{pH}$ of the soil was 6.1; the content of humus was $1.1 \%$. The average precipitation in the growing season was $320 \mathrm{~mm} / \mathrm{m}^{2}$, with an average daily temperature of $14.9^{\circ} \mathrm{C}$. Fruits were stored until preparation and analysis at $-21^{\circ} \mathrm{C}$.

Some fruits were cut to improve steam migration and then they were free-dried. Lyophilisation process was conducted for $72 \mathrm{~h}$ at the vacuum of 1.030 mbar, condensation temperature of $-52{ }^{\circ} \mathrm{C}$ and shelf temp. of $+24{ }^{\circ} \mathrm{C}$ (Christ, Germany).

\section{Methods}

\section{Extract preparation}

Extraction of test samples was done using the method described in previous study [16]. The fruit skin was cut to facilitate higher migration of phytocompounds to the extractant. Fruits were macerated with distilled water at fresh fruit ratio: extractant $1: 5(\mathrm{~m} / \mathrm{v})$ for $30 \mathrm{~min}$ at $40{ }^{\circ} \mathrm{C}$. Then, the extracts were seeped through paper filters (Alfachem, Poznan, Poland). The prepared extracts were stored in sealed tubes until examination at $-21^{\circ} \mathrm{C}$.

\section{Antioxidant capacity}

Antioxidant capacity against ABTS cationic radical (TEAC) assay was performed using own method [16] based on Bartosz's analytical protocol [17]. First, 2,2'-azino-bis(3-ethylbenzothiazoline-6-sulfonic acid) (ABTS) stock solution was prepared by dissolving $19.5 \mathrm{mg}$ ABTS (Sigma-Aldrich, Poland) and $3.3 \mathrm{mg}$ potassium persulphate ( $\mathrm{POCH}$, Poland) in $7 \mathrm{~mL}$ phosphate buffer $(\mathrm{pH} 7.0,0.1 \mathrm{M})$. Then, the stock solution was kept in dark for $18 \mathrm{~h}$ at ambient temperature. After that time, the working solution was prepared by diluting the stock solution 50-fold. The absorbance of the resulting working solution was 1.100 (Metertech SP-830, 
Taiwan). The antioxidant activity against ABTS was carried out according to the following procedure: The absorbance at a wavelength of $414 \mathrm{~nm}$ was measured for $980 \mu \mathrm{L}$ of the working solution $\left(A_{0}\right)$ in $1 \mathrm{~mL}$ microcuvette. Then, the tested extract was added to the microcuvette at the quantity of $20 \mu \mathrm{l}$ and was mixed twice using an automatic pipette (HTL, Poland). The absorbance $\left(A_{1}\right)$ was read $40 \mathrm{~s}$ after the extract was added. The antioxidant capacity $(\%)$ was calculated according to the following equation:

$\%=\frac{A_{0}-A_{1}}{A_{0}} \times 100 \%$.

Distilled water was used as a blank. A calibration curve was determined based on Trolox (Sigma-Aldrich, Poland) standard solutions. The linearity $\left(r^{2}\right)$ of the calibration curve was $0.9829(y=291.73 x-4.752)$. Three independent specimens were made for each extract. Final results were calculated as $\mu \mathrm{mol}$ Trolox equivalents (TE)/g of dried mass (d.m.) of extract according to the following equation:

$\mathrm{TEAC}=\frac{x}{d_{\mathrm{m}}} \times D \times V_{\mathrm{m}}$,

where $X$-Trolox concentration estimated from the calibration curve $[\mu \mathrm{mol} / \mathrm{mL}] ; V_{\mathrm{m}}$-volume of the extract used for dry mass determination $[\mathrm{mL}] ; d_{\mathrm{m}}$-dry mass of the tested extract $[\mathrm{g}] ; D$ —extract dilution [1:5:10].

Ferric-reducing antioxidant capacity (FRAP) assay was performed using O'Sullivan et al.'s [18] method. FRAP reagent was prepared by dissolving $78 \mathrm{mg}$ of 2,4,6-tris(2pyridyl)-s-triazine (Sigma-Aldrich, Poland), $1.35 \mathrm{~g}$ of $\mathrm{FeCl}_{3}$ (POCH, Poland), $833 \mu \mathrm{L}$ of concentrated hydrochloric acid (Chempur, Poland) and $20 \mathrm{~mL}$ of demineralised water in pure methanol (Honeywell, United Kingdom), up to the final volume of $250 \mathrm{~mL}$. The entire volume of $200 \mu \mathrm{L}$ diluted or crude preparation of tested extract was added to a test tube with $800 \mu \mathrm{L}$ of distilled water and mixed. Next, $2 \mathrm{~mL}$ FRAP reagent was added. After $30 \mathrm{~min}$, the absorbance was measured at $593 \mathrm{~nm}$ (SP880, Metertech, Taiwan). Each extract was tested in triplicate. The calibration curve was based on aqueous $\mathrm{FeSO}_{4} \times 6 \mathrm{H}_{2} \mathrm{O}$ (Arcos Organics, the United Kingdom) standard solutions $(y=1.2375 x+0.4861)$. A curve linearity factor $\left(r^{2}\right)$ was 0.9613 . Final results were given at $\mu \mathrm{mol} \mathrm{Fe}^{2+}$ equivalent (FE)/g d.m. analogically to TEAC assay.

\section{Total flavonoid content}

Extracts used in this study were prepared analogically to the ones analysed in the antioxidant capacity test.

The total flavonoid content (TFC) was determined using the method of Meda et al. [19], with own modifications. In a test tube, $1 \mathrm{~mL}$ of $2 \% \mathrm{AlCl}_{3}$ ( $\mathrm{POCH}$, Poland) dissolved in methanol (Honeywell, the United Kingdom) was mixed with $1 \mathrm{~mL}$ of tested extract. After 10-min conditioning in the absence of daylight, the absorbance at $415 \mathrm{~nm}$ was measured (SP830, Metertech, Taiwan). All the extracts were analysed in triplicate. As a negative sample, the mixture of $1 \mathrm{~mL}$ of pure methanol (Honeywell, the UK) and the tested extract was applied. The final result was the corrected absorbance value $\left(A^{\prime}\right)$ that was obtained by subtracting the absorbance of a negative sample $\left(A_{\mathrm{n}}\right)$ from the positive ones $(A)$, using the following equation:

$A^{\prime}=A-A_{\mathrm{n}}$.

The standard curve was based on quercetin (SigmaAldrich, Germany) standard solutions ( $r^{2}$ 0.9989; $y=12.922 x-0.0246)$. The final results are given in $\mathrm{mg}$ quercetin equivalents $(\mathrm{QE}) / \mathrm{g}$ d.m. according to the following equation:

$\mathrm{TFC}=X \times \frac{V}{d_{\mathrm{m}}}$,

where $X$-quercetin concentration estimated from the calibration curve $[\mathrm{mg} / \mathrm{mL}] ; V$ - tested extract volume used for dry mass determination $[\mathrm{mL}] ; d_{\mathrm{m}}$-dry mass $[\mathrm{g}]$.

\section{Total anthocyanin content}

Extracts used in this study were prepared analogically to the ones analysed in the antioxidant capacity test.

The total anthocyanin content was determined using the method of Lee et al. [20], with slight modifications. The difference in absorbance (SPECORD S40, Analityk Jena, Germany) was measured between two wavelengths and buffer media, in which $0.4 \mathrm{~mL}$ of tenfold diluted crude extract was mixed with $3.6 \mathrm{~mL}$ of $25 \mathrm{mM} \mathrm{KCl}$ solution in $0.1 \mathrm{M} \mathrm{HCl}$ $(\mathrm{pH} 1.0)$ or $3.6 \mathrm{~mL}$ sodium acetate buffer $(\mathrm{pH} 4.5)$. The total anthocyanin content (TAC) was calculated using the following equation:

$\mathrm{TAC}=\frac{\left[\left(A_{510}-A_{700}\right)_{\mathrm{pH} 1.0}-\left(A_{510}-A_{700}\right)_{\mathrm{pH} 4.5}\right] \times 44.92}{269 \times d_{\mathrm{m}}}$,

where $A_{510}$ is the absorbance at $\lambda=510 \mathrm{~nm} ; A_{700}$ is the absorbance at $\lambda=700 \mathrm{~nm} ; d_{\mathrm{m}}$ is dry mass [g].

Each sample was tested in triplicate and the results were given in $\mathrm{mg}$ cyanidin-3-glycoside equivalents (CGE) per $\mathrm{g}$ d.m.

\section{Determination of loganic acid}

First, freeze-dried fruits of cornelian cherry were wiped through a sieve with a mesh diameter of $0.5 \mathrm{~mm}$. The whole amount of $1.0 \mathrm{~g}$ wiped fruits was transferred to a $10 \mathrm{~mL}$ 
volumetric flask and then filled with distilled water. The solution was incubated in a sonic bath for $1 \mathrm{~h}$ at a temperature of $40{ }^{\circ} \mathrm{C}$. After that point, the extract was filtered through a paper filter and $0.2 \mu \mathrm{L}$ filter to dispose of mechanical impurities. Each $5 \mu \mathrm{L}$ injection of the tested extract was conducted in triplicate. The determination was conducted using Dionex Thermoline (Fisher Scientific, the United Kingdom) UPLC equipped with UltiMate 3000 DAD detector. The analyte migrated through Zorbax SB-C18 Rapid Resolution column $(4.6 \times 100 \mathrm{~mm}, 3.5$-Micorn $)$ and was analysed at a wavelength of $240 \mathrm{~nm}$. The eluent had $1.0 \mathrm{~mL} /$ min flow and contained two phases: $\mathrm{A}-0.1 \%$ acetic acid and B-methanol at gradient: 0-4 min-1\% B, 18 min$12 \%$ B, 22 min-20\% B, 35 min-35\% B, 40 min-95\% B, 40-50 min-95\% B. LA was detected at $23.5 \mathrm{~min}$. after injection. The calibrated curve involved 11 loganic acid (LA; Sigma-Aldrich, Germany) standard solutions $(0.48-5.76 \mathrm{mg}$ / $\mathrm{mL}$ ). The curve was validated according to ICH regulations and demonstrated significant linearity $\left(r^{2} 0.9963\right.$; $y=18.563 x-3.2055)$. Finally, LA content was calculated per g d.m.

\section{Hypoglycaemic effect}

Freeze-dried fruits of cornelian cherry were wiped through a sieve with a mesh diameter of $0.5 \mathrm{~mm}$. After that point, $10 \mathrm{mg}$ of wiped fruits was transferred to a $10 \mathrm{~mL}$ volumetric flask and then filled to this volume with water. Next, the flask was shaken for $1 \mathrm{~h}$ at a temperature of $37{ }^{\circ} \mathrm{C}$. Decanted solutions of $C$. mas extracts were subjected to $\alpha$-glucosidase inhibition study at concentration ranges: $\mathrm{cv}$.

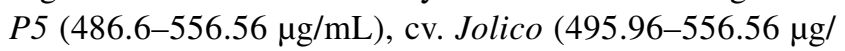
$\mathrm{mL})$, cv. Szafer $(500-580 \mu \mathrm{g} / \mathrm{mL})$. Reference sample set consisted of aqueous acarbose (Sigma-Aldrich, Poland) solutions at $1-5 \mathrm{mg} / \mathrm{mL}$ concentrations. Separate three trials were prepared for each tested concentration. Inhibition of $\alpha$-glucosidase was determined in $C$. mas aqueous extracts by using Telagari et al.'s [21] spectrophotometric method, with minor modifications. Briefly, $50 \mu \mathrm{L}$ of sample solution or acarbose (positive control) with various concentrations- $50 \mu \mathrm{L}$ of $0.1 \mathrm{M}$ phosphate buffer $(\mathrm{pH}$ $6.8)$ and $30 \mu \mathrm{L}$ of $\alpha$-glucosidase solution $(1.0 \mathrm{U} / \mathrm{mL})$-was pre-incubated in 96 well plates at $37{ }^{\circ} \mathrm{C}$ for $15 \mathrm{~min}$. Next, $20 \mu \mathrm{L}$ of $5 \mathrm{mM} p$-nitrophenyl- $\alpha$-D-glucopyranoside ( $p$ NPG, Sigma-Aldrich, Poland) solution in $0.1 \mathrm{M}$ phosphate buffer (pH 6.8) was added and incubated at $37^{\circ} \mathrm{C}$ for $20 \mathrm{~min}$. The reaction terminated after adding $100 \mu \mathrm{L}$ of sodium carbonate $\mathrm{Na}_{2} \mathrm{CO}_{3}(0.2 \mathrm{M})$ into the mixture. The absorbance of liberated $p$-nitrophenol was measured at $405 \mathrm{~nm}$ (Multiskan GO 1510, Thermo Fisher Scientific, Vantaa, Finland). The absorbance of enzyme solution, but without plant extracts/ acarbose, served as the control with total enzyme activity.
We used the absorbance in the enzyme's absence as a blind control. The enzyme inhibition rate, expressed as a percentage of inhibition, was calculated according to the following equation:

\%inhibition activity $=\left(\frac{A_{\mathrm{C}}-A_{\mathrm{S}}}{A_{\mathrm{S}}}\right) \times 100$,

where $A_{\mathrm{C}}$ is the absorbance of the control (100\% enzyme activity) and $A_{\mathrm{S}}$ is the absorbance of the tested sample ( $C$. mas extract or acarbose).

Two independent experiments were carried out in triplicate for the extracts tested. The results were expressed as means $\pm \mathrm{SD}$. The $\mathrm{IC}_{50}$ values were calculated with OriginPro 9 (Origin soft, Germany) software using nonlinear regression.

\section{Permeability of LA}

Permeability was determined using the parallel artificial membrane permeability assay (PAMPA). To simulate cellular membranes in the digestive system (GIT), a model system was composed for the tested substance. The model was composed of two 96-well microplates covering each other ("sandwich-like") and were separated from each other by film soaked in lipid solution simulating cellular membrane. To avoid gravitational diffusion, the lower microplate was the donor and the upper one was the acceptor. The plates were incubated for $45 \mathrm{~min}$ at a temperature of $37{ }^{\circ} \mathrm{C}$ with continuous shaking at $50 \mathrm{rpm}$.

Apparent permeability coefficients $\left(P_{\text {app }}\right)$ were used for the determination of LA permeability. They were calculated using the following equation:

$$
P_{\text {app }}=\frac{-\ln \left(1-\frac{c_{\mathrm{A}}}{c_{\text {equilibrium }}}\right)}{S \times\left(\frac{1}{V_{\mathrm{D}}}+\frac{1}{V_{\mathrm{A}}}\right) \times t},
$$

where $V_{\mathrm{D}}$-donor part volume $\left[\mathrm{cm}^{3}\right], V_{\mathrm{A}}$-acceptor part volume $\left[\mathrm{cm}^{3}\right], c_{\text {equilibrium }}$ equilibrium concentration, $c_{\mathrm{A}}$-concentration in acceptor part, $S$-membrane surface $\left[\mathrm{cm}^{2}\right], t$-incubation time [s]. To interpret collected data, the assumption was made that systems with $P_{\text {app }}<1 \times 10^{-6} \mathrm{~cm} / \mathrm{s}$ would be classified as less permeable and those with $P_{\text {app }}>1 \times 10^{-6} \mathrm{~cm} / \mathrm{s}$ - as highly permeable.

\section{Statistical analysis}

For each tested parameter, statistical differences between samples were identified using ANOVA test $(\alpha=0.05)$. The correlation between tested parameters was determined 
using principal component analysis (PCA) and Spearman's correlation matrix. For the analysis, Statistica 13.3 software (Statsoft, Poland) was used.

\section{Human and animal rights statement}

This article does not contain any studies with human participants or animals performed by any of the authors.

\section{Results}

Antioxidant capacity against ABTS radical cation ranged between 1.78 and $43.54 \mu \mathrm{mol} \mathrm{TE} / \mathrm{g} \mathrm{d}$.m. (Table 1). The results for cv. Szafer were outstandingly higher than other cultivars. Similar results were delivered by FRAP test. While cvs. P5 and Jolico demonstrated similar FRAP values (127.39 and $135.38 \mu \mathrm{mol} \mathrm{Fe}{ }^{2+} / \mathrm{g}$ d.m., respectively), the results for cv. Szafer were two-fold higher $(289.40 \mu \mathrm{mol}$ $\mathrm{Fe}^{2+} / \mathrm{g}$ d.m.).
Total anthocyanin content was the most varied parameter for the samples tested. Each cultivar differed significantly from others (Table 1). Szafer was the richest in anthocyanins (5.70 mg CGE/g d.m.) while $P 5$ was the poorest (1.11 mg CGE/g d.m.). Among tested cultivars, TFC was significantly lower in $P 5$ (1.11 mg QE/g d.m.), whereas in other cultivars, the amount of total flavonoids was similar (Table 1). Chromatographic analysis of LA provided similar data for all tested cultivars (Table 1). Among the tested compounds, the poorest results were obtained by cv. Jolico $(2.44 \mathrm{mg} / \mathrm{g}$ d.m.), and the richest ones by Szafer $(2.72 \mathrm{mg} / \mathrm{g} \mathrm{d}$ d.m.). A freeze-drying process of Cornus mas decreased water content to $5.74-7.44 \%$, and LA content in lyophilisate was also the lowest in $\mathrm{Jol}$ ico and the highest in Szafer (Table 1).

Similar to LA content, hypoglycaemic potential differed insignificantly among the tested cultivars (Fig. 1a). The strongest $\alpha$-glucosidase inhibitor was P5 $\left(\mathrm{IC}_{50} 171.19 \mu \mathrm{g} /\right.$ $\mathrm{mL}$ ), while the poorest was Szafer $\left(\mathrm{IC}_{50} 174.53 \mu \mathrm{g} / \mathrm{mL}\right)$.

Table 1 Loganic acid and other phytochemicals content in tested C. mas cultivars

\begin{tabular}{|c|c|c|c|c|c|c|c|}
\hline Cultivar & $\begin{array}{l}\text { Water content in } \\
\text { lyophilisate }(\%)\end{array}$ & $\begin{array}{l}\text { LA in } \\
\text { lyophilisate } \\
{[\mathrm{mg} / \mathrm{g}]}\end{array}$ & $\begin{array}{l}\text { Aqueous extract } \\
\text { [mg LA/g d.m.] }\end{array}$ & $\begin{array}{l}\text { TEAC }[\mu \mathrm{mol} \mathrm{TE} / \mathrm{g} \\
\text { d.m] }\end{array}$ & $\begin{array}{l}\text { FRAP }[\mu \mathrm{mol} \\
\mathrm{Fe}^{2+} / \mathrm{g} \text { d.m] }\end{array}$ & $\begin{array}{l}\text { TFC [mg QE/g } \\
\text { d.m] }\end{array}$ & $\begin{array}{l}\text { TAC }[\mathrm{mg} \text { CGE/g } \\
\text { d.m] }\end{array}$ \\
\hline P5 & $5.74^{\mathrm{a}} \pm 0.05$ & $2.50^{\mathrm{a}} \pm 0.08$ & $2.65^{\mathrm{a}} \pm 0.08$ & $1.78^{\mathrm{a}} \pm 0.25$ & $127.39^{\mathrm{a}} \pm 3.28$ & $1.11^{\mathrm{a}} \pm 0.23$ & $1.11^{\mathrm{a}} \pm 0.03$ \\
\hline Jolico & $7.44^{\mathrm{b}} \pm 0.15$ & $2.26^{\mathrm{a}} \pm 0.03$ & $2.44^{\mathrm{a}} \pm 0.03$ & $11.91^{\mathrm{a}} \pm 4.21$ & $135.38^{a} \pm 2.24$ & $4.15^{\mathrm{b}} \pm 0.05$ & $4.29^{\mathrm{b}} \pm 0.13$ \\
\hline Szafer & $7.00^{\mathrm{b}} \pm 0.30$ & $2.53^{\mathrm{a}} \pm 0.26$ & $2.72^{\mathrm{a}} \pm 0.11$ & $43.54^{\mathrm{b}} \pm 13.54$ & $289.40^{\mathrm{b}} \pm 25.04$ & $4.51^{b} \pm 0.25$ & $5.70^{c} \pm 0.10$ \\
\hline
\end{tabular}

$N=3$

$T E A C$ antiradical capacity against $\mathrm{ABTS}^{\circ}$, FRAP ferric reducing antioxidant potential, $T F C$ total flavonoid content, $T A C$ total anthocyanins content

Lowercase superscript letters indicate significant differences between samples $(\alpha=0.05)$
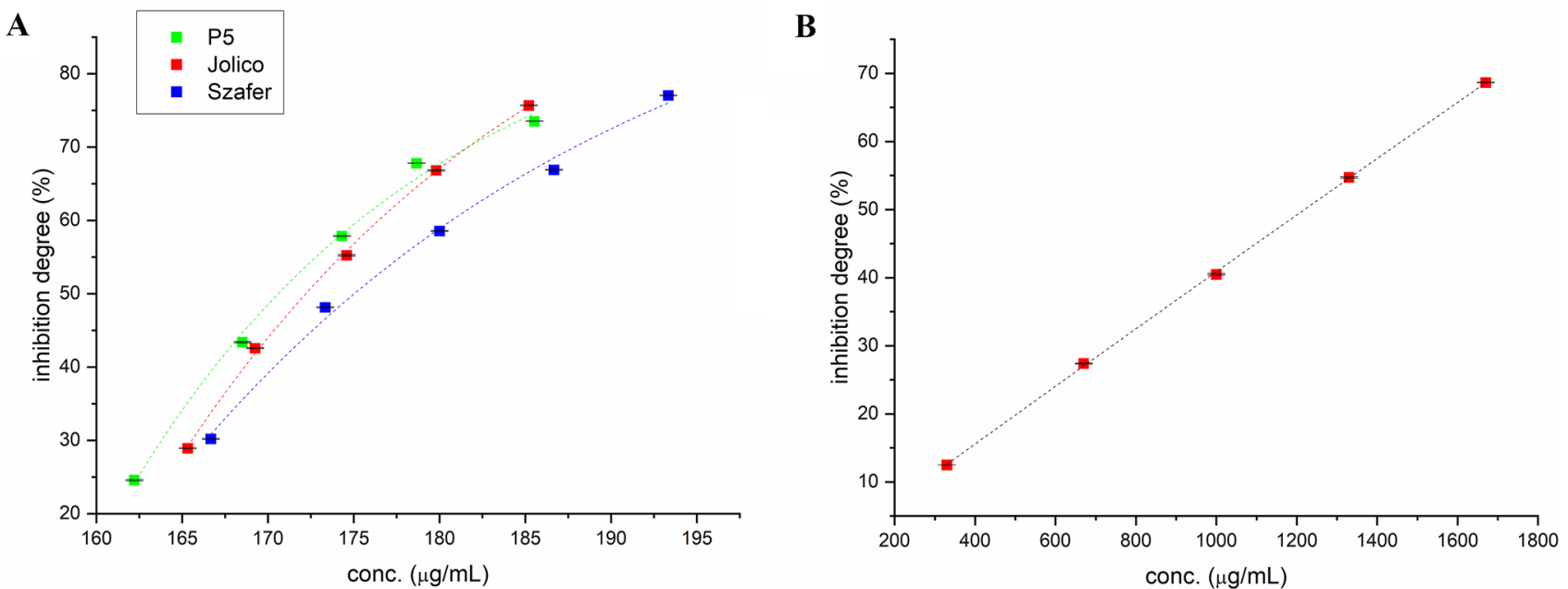

Fig. 1 Inhibition (\%) of $\alpha$-glucosidase by tested Corni fructus samples (a) and reference standard—acarbose (b). $N=3$ 


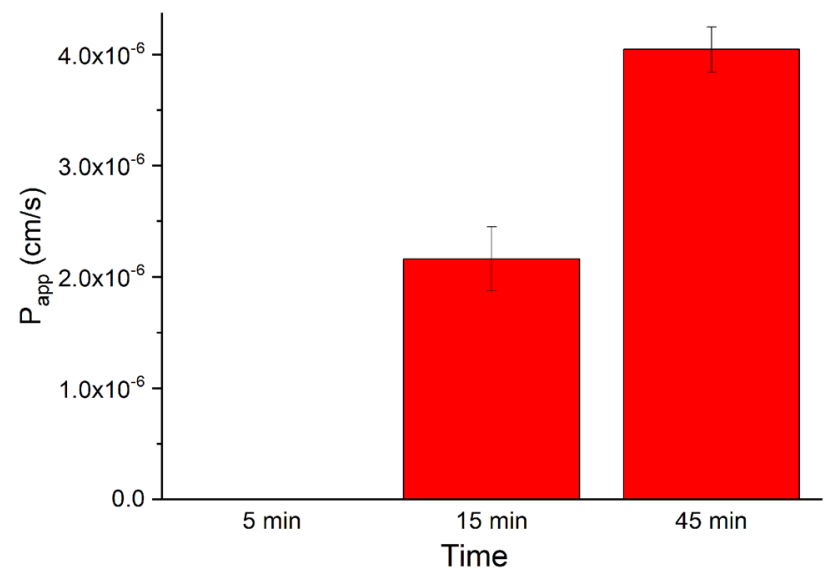

Fig. 2 Apparent permeability $\left(P_{\text {app }}\right)$ of loganic acid through gastric cell membranes in vitro. $N=3$

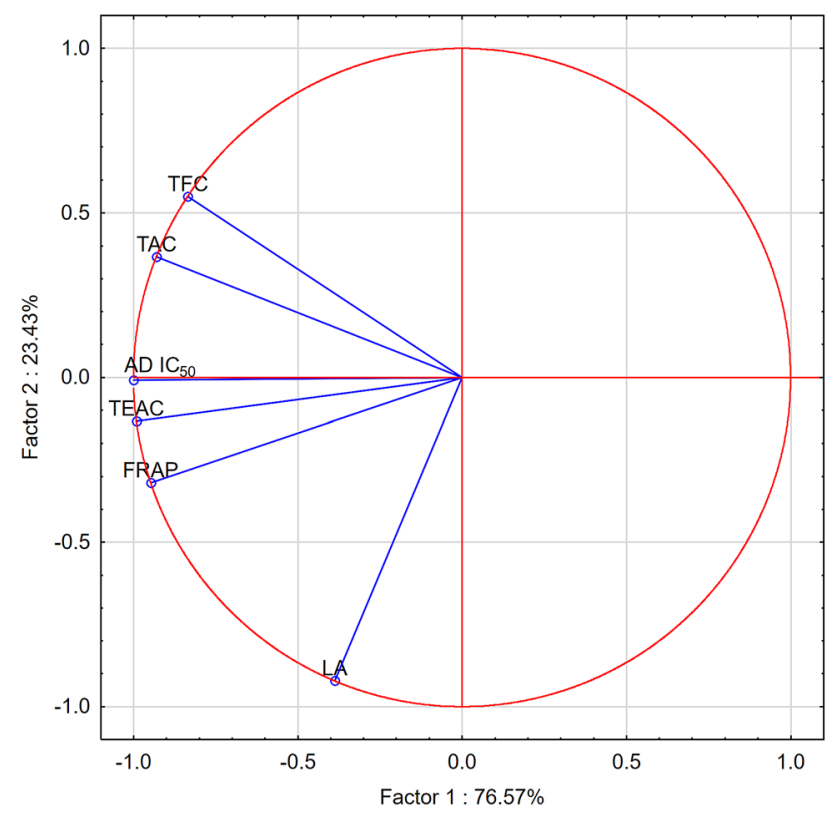

Fig. 3 Principal scatter plot for tested parameters. HG $\mathrm{IC}_{50}-\alpha$-glucosidase inhibition $\left(\mathrm{IC}_{50}\right), F R A P$ ferric reducing antioxidant potential, $L A$ loganic acid content, TAC total anthocyanin content, TFC total flavonoid content

The inhibitory activity of the reference standard was significantly lower. The mean $\mathrm{IC}_{50}$ was $1.22 \mathrm{mg} / \mathrm{mL}$.

After $5 \mathrm{~min}$ of simulated permeability test, LA peaks were registered at noise level, and therefore $P_{\text {app }}$ equalled zero (Fig. 2). For samples measured at a timeframe of 15 and $45 \mathrm{~min}$, permeability reached the limit of $1 \times 10^{-6} \mathrm{~cm} / \mathrm{s}$.

PCA analysis showed that all tested parameters represented negative input to Factor 1 ( $76.57 \%$ of all effects), while in the range of Factor 2, they were more diverse
(Fig. 3). A particularly close relation was found between the hypoglycaemic effect ( $\left.\mathrm{HG} \mathrm{IC}_{50}\right)$ and antioxidant capacity measured against ABTS radical using FRAP method. Surprisingly, LA content apparently distinguishes from HG $\mathrm{IC}_{50}$. This correlation was validated by Pearson's $r$ correlation factor (Table 2). Significant correlations were observed between $\mathrm{HG} \mathrm{IC}_{50}$ and ABTS scavenging capacity, $\mathrm{HG} \mathrm{IC} 50$ and iron reducing ability and results of TEAC and FRAP tests. Moreover, there was a strong relation noted between $\alpha$-glucosidase inhibition and TAC. The relation between LA content and $\mathrm{HG} \mathrm{IC}_{50}$ was positive, but significantly poorer than the relation of $\mathrm{HG} \mathrm{IC}_{50}$ with flavonoids and anthocyanins.

\section{Discussion}

The data collected on antioxidant properties of C. mas are in line with results of other studies. In the previous study, the authors indicated that Szafer had the highest antioxidant potential against ABTS, but poorer against DPPH radical [16]. Gasstoł et al. [22] noted that mean ferric FRAP value for cornelian cherry juice was approximately $23.5 \mu \mathrm{mol}$ $\mathrm{Fe}^{2+} / \mathrm{mL}$, and de Biaggi et al. [23] observed FRAP levels at $20.41 \mu \mathrm{mol} \mathrm{Fe} \mathrm{F}^{2+} / \mathrm{g}$ of fresh weight. In the antioxidant capacity tests, LA content had the strongest correlation with ferric-reducing capacity, although that relation was not significant (Fig. 3, Table 2). No significant relation was found between LA and TEAC, either.

In reference positions, total flavonoid content was found to vary depending on cultivars and years of harvesting (2.58-2.69 mg/g d.m.) [24]. The predominant compounds were quercetin glycosides, kaempferol and ellagic acid [5, 25]. De Biaggi et al. [23] in their study also observed meaningful amounts of quercitrin, rutin and hyperoside. Similar to the flavonoid content, the anthocyanin content also results from numerous environmental factors. In a broader study conducted by Kucharska et al. [14], the first cultivar had $1.35 \mathrm{mg} \mathrm{CGE} / \mathrm{g}$ of fresh weight. As the water content in $C$. mas is threefold higher than the amount of dry matter [5], it should be noted that TAC value in that study is much higher than the cited position. As it was noted in the previous studies concerning cornelian cherry, loganic acid is the most prevalent iridoid in cornelian cherry fruits $[7,26]$. However, other iridoids such as cornuside and sweroside were also reported $[5,7,27]$. The results of this study $(2.44-2.72 \mathrm{mg} / \mathrm{g}$ d.m.) are comparable with data collected by Kucharska et al. [11]. The authors of that paper noted that LA content in cv. Szafer was approx. $2.34 \mathrm{mg} / \mathrm{g}$ d.m., and in Jolico it varied from 2.69 to $2.91 \mathrm{mg} / \mathrm{g} \mathrm{d}$.m., depending on the time when the fruits were collected. 
Table. 2. Correlations ( $r$ values) between tested Cornus mas parameters

\begin{tabular}{|c|c|c|c|c|c|c|}
\hline Variable & LA & AD IC $_{50}$ & TEAC & FRAP & TFC & TAC \\
\hline LA & 1.000000 & 0.395866 & 0.506821 & 0.661187 & -0.183468 & 0.023496 \\
\hline AD IC $_{50}$ & 0.395866 & 1.000000 & 0.992262 & 0.950676 & 0.830092 & 0.927356 \\
\hline TEAC & 0.506821 & 0.992262 & 1.000000 & 0.981832 & 0.754433 & 0.873722 \\
\hline FRAP & 0.661187 & 0.950676 & 0.981832 & 1.000000 & 0.616180 & 0.765549 \\
\hline TFC & -0.183468 & 0.830092 & 0.754433 & 0.616180 & 1.000000 & 0.978444 \\
\hline TAC & 0.023496 & 0.927356 & 0.873722 & 0.765549 & 0.978444 & 1.000000 \\
\hline
\end{tabular}

Blue, red and grey colours indicate positive (+), negative (-) and no relation between variables, respectively. The darker the colour the stronger the relation was

$A D I C_{50} \alpha$-gluosidase inhibition (IC50), FRAP ferric reducing antioxidant potential, LA loganic acid content, TAC total anthocyanin content, TFC total flavonoid content

In this study, a significantly high potential of C. mas fruits to inhibit $\alpha$-glucosidase was observed. The $\mathrm{IC}_{50}$ values show that cornelian cherry fruits had approx. sevenfold higher inhibitory potential against $\alpha$-glucosidase than acarbose standard (Fig. 1). However, the differences between the tested cultivars were not significant. Hypoglycaemic properties of the tested extracts may rather depend on the extractant used than on the cultivar deviation.

Plants produce compounds which act as a natural repellant against pests and pathogens. That group includes inhibitors of insect digestive enzymes, such as $\alpha$-amylase and protease inhibitors. These inhibitors may be applied in the treatment of human diseases of affluence [28]. Numerous plants synthesize $\alpha$-amylase and $\alpha$-glucosidase inhibitors, i.e. enzymes decreasing glucose absorption from the gastric tract and, therefore, lowering glucose levels in the blood. A root of barberry (Berberis vulgaris) and a leaf of black mulberry (Morus nigra) have been commonly used in diabetes nutrition therapy. Nonetheless, the inhibitory activity of the above-mentioned plants results from alkaloid compounds [29-31].

The research results showed that iridoids may act as inhibitors of enzymes responsible for the diseases of affluence. However, the activities observed in those studies depend on a broad range of factors, i.e. a methodology applied and raw material tested. In a similar study, the inhibitory activity against pancreatic lipase was the strongest for ethanolic C. mas extract, while the poorest for methanolic one. In the case of $\alpha$-amylase, the most efficient inhibitor was the methanolic extract and the weakest was aqueous extract [9]. In a clinical study conducted by Soltani et al. [32], daily intake of C. mas extract affected insulin levels positively and reduced triglyceride serum levels in patients suffering from diabetes mellitus type 2 . In previous experiments, hypoglycaemic action was considered an effect of flavonoids. You et al. [33] noted that ellagic acid inhibitory activity is approximately 500-fold higher than of catechin and sevenfold higher than of quercetin. In in silico study, quercetin was found to be one of the strongest $\alpha$-glucosidase inhibitors. The inhibitory activity is induced by hydroxyl groups located at either 5-, 7- or 8-positions of the A-ring, at 3- and 4-positions of the B-ring and at C-ring of the flavonoid structure [34]. In the study by Sozański et al. [7], rabbits on rich cholesterol diet with the administration of loganic acid with concentration equal to its content in C. mas had lower levels of lipid serum and LDL cholesterol, however, the strongest effect was observed in rabbits receiving C. mas anthocyanins. In turn, administration of loganic acid more effectively reduced liver peroxisome proliferator-activated receptor expression and tumour necrosis factor $\alpha$ activity. Those results indicate high antioxidant activity of loganic acid, which also might have a high structural affinity to other enzymes, including those regulating glucose metabolism.

In this study, no strong relation could be found between loganic acid content and $\alpha$-glucosidase inhibition. Thus, the observed inhibitory effect of cornelian cherry fruits might be a synergic effect of total phytocompounds present in the fruits.

The high permeability of LA (over $1 \times 10^{-6} \mathrm{~cm} / \mathrm{s}$ ) observed after 15 and 45 min of the simulation allows characterisation of LA as extra bioavailable substance. The available literature on the subject does not contain any information concerning gastric cell permeability or biological absorption of LA. For anthocyanins, transport through gastric membranes resulted in 5-10\% of total origin content [12]. In other study, authors noted that in vitro gastric digestion process had no negative effect on both the anthocyanins and total antioxidant potential of digested cornelian cherry extracts [35]. This could be driven by changes in the content of individual anthocyanins. Hence, in-depth 
analyses — concerning also in vivo studies — should be conducted in the future.

The literature about cornelian cherry's functional properties is very extensive. This paper broadens the current state of knowledge, indicating the relations between a given cultivar and inhibitory activity against $\alpha$-glucosidase. Despite the novelty of the results, the therapeutic effect of $C$. fructus needs confirmation in future studies.

\section{Conclusions}

Although loganic acid has high permeability, its content in C. mas is insufficient to have a prevalent impact on the hypoglycaemic and antioxidant potential. These two properties seem to depend on total flavonoid and total anthocyanin content. Further research into hypoglycaemic and total antidiabetic potential of $C$. mas is required, and it needs to involve permeability study of all compounds present in the fruit.

Author contributions Conceptualization: OS and JK; data curation: OS; formal analysis: OS; investigation: OS and JC; methodology: OS and JC; project administration: OS; resources: JK; software: OS and JC; supervision: JK; validation: JK; visualization: OS and JC; writing: —original draft: OS; writing—review and editing: JK.

Funding This research was supported by statutory funds of the Department of Gastronomy Sciences and Functional Foods of Poznań University of Life Sciences, Grant number 506.751.03.00.

Availability of data and materials Complete data will be available on demand addressed to the corresponding author.

Code availability Data and calculations have been stored as Origin spreadsheet files and Microsoft Excel spreadsheets. Raw data involving secondary metabolites and antioxidant potential had been written in a laboratory notebook and then were rewritten to Microsoft Excel spreadsheet files.

\section{Compliance with ethical standards}

Conflict of interest The authors declare that they have no conflict of interest.

Open Access This article is licensed under a Creative Commons Attribution 4.0 International License, which permits use, sharing, adaptation, distribution and reproduction in any medium or format, as long as you give appropriate credit to the original author(s) and the source, provide a link to the Creative Commons licence, and indicate if changes were made. The images or other third party material in this article are included in the article's Creative Commons licence, unless indicated otherwise in a credit line to the material. If material is not included in the article's Creative Commons licence and your intended use is not permitted by statutory regulation or exceeds the permitted use, you will need to obtain permission directly from the copyright holder. To view a copy of this licence, visit http://creativecommons.org/licenses/by/4.0/.

\section{References}

1. Fernandes SS, Coelho MS, de las Salas-Mellado M (2019) Bioactive compounds as ingredients of functional foods: polyphenols, carotenoids, peptides from animal and plant sources new. Bioact Compd. https://doi.org/10.1016/B978-0-12-814774-0.00007-4

2. Poschner S, Maier-Salamon A, Thalhammer T, Jäger W (2019) Resveratrol and other dietary polyphenols are inhibitors of estrogen metabolism in human breast cancer cells. J Steroid Biochem Mol Biol 190:11-18. https://doi.org/10.1016/J.JSBMB .2019.03.001

3. Hoskin RT, Xiong J, Esposito DA, Lila MA (2019) Blueberry polyphenol-protein food ingredients: the impact of spray drying on the in vitro antioxidant activity, anti-inflammatory markers, glucose metabolism and fibroblast migration. Food Chem 280:187194. https://doi.org/10.1016/J.FOODCHEM.2018.12.046

4. Czerwinska ME, Melzig MF (2018) Cornus mas and Cornus officinalis-analogies and differences of two medicinal plants traditionally used. Front Pharmacol 9:1-28

5. Szczepaniak OM, Kobus-Cisowska J, Kusek W, Przeor M (2019) Functional properties of Cornelian cherry (Cornus mas L.): a comprehensive review. Eur Food Res Technol 245:2071-2087. https://doi.org/10.1007/s00217-019-03313-0

6. Szumny D, Sozański T, Kucharska AZ et al (2015) Application of cornelian cherry iridoid-polyphenolic fraction and loganic acid to reduce intraocular pressure. Evid Based Complement Altern Med. https://doi.org/10.1155/2015/939402

7. Sozański T, Kucharska AZ, Rapak A et al (2016) Iridoid-loganic acid versus anthocyanins from the Cornus mas fruits (cornelian cherry): common and different effects on diet-induced atherosclerosis, PPARs expression and inflammation. Atherosclerosis 254:151-160. https://doi.org/10.1016/j.atherosclerosis .2016.10.001

8. Jiang W-L, Zhang S-P, Hou J, Zhu H-B (2012) Effect of loganin on experimental diabetic nephropathy. Phytomedicine 19:217222. https://doi.org/10.1016/j.phymed.2011.08.064

9. Świerczewska A, Buchholz T, Melzig MF, Czerwińska ME (2019) In vitro $\alpha$-amylase and pancreatic lipase inhibitory activity of Cornus mas L. and Cornus alba L. fruit extracts. J Food Drug Anal 27:249-258. https://doi.org/10.1016/J.JFDA.2018.06.005

10. Piekarska J, Szczypka M, Kucharska AZ, Gorczykowski M (2018) Effects of iridoid-anthocyanin extract of Cornus mas L. on hematological parameters, population and proliferation of lymphocytes during experimental infection of mice with Trichinella spiralis. Exp Parasitol 188:58-64. https://doi.org/10.1016/j.exppa ra.2018.03.012

11. Nizioł-Lukaszewska Z, Wasilewski T, Bujak T, Osika P (2017) Iridoids from Cornus mas L. and their potential as innovative ingredients in cosmetics. Pol J Chem Technol 19:122-127. https ://doi.org/10.1515/pjct-2017-0078

12. Kawa-Rygielska J, Adamenko K, Kucharska AZ, Piórecki N (2018) Bioactive compounds in cornelian cherry vinegars. Molecules. https://doi.org/10.3390/molecules23020379

13. del Carmen RM, Giner R, Máñez S, Ríos J (1994) Structural considerations on the iridoids as anti-inflammatory agents. Planta Med 60:232-234. https://doi.org/10.1055/s-2006-959465

14. Tenuta MC, Deguin B, Loizzo MR et al (2020) Contribution of flavonoids and iridoids to the hypoglycaemic, antioxidant, and nitric oxide (NO) inhibitory activities of Arbutus unedo L. Antioxidants 9:184. https://doi.org/10.3390/antiox9020184

15. Bendary E, Francis RR, Ali HMG et al (2013) Antioxidant and structure-activity relationships (SARs) of some phenolic and anilines compounds. Ann Agric Sci 58:173-181. https://doi. org/10.1016/j.aoas.2013.07.002 
16. Szczepaniak OM, Ligaj M, Kobus-Cisowska J et al (2019) Application for novel electrochemical screening of antioxidant potential and phytochemicals in Cornus mas extracts. CyTA J Food 17:781-789. https://doi.org/10.1080/19476337.2019.1653378

17. Bartosz G (2003) Druga twarz tlenu: wolne rodniki w przyrodzie [Other face of Oxygen: free radicals in nature]. PWN Press, Warsaw

18. O'Sullivan AM, O'Callaghan YC, O'Connor TP, O'Brien NM (2013) Comparison of the antioxidant activity of commercial honeys, before and after in-vitro digestion. Pol J Food Nutr Sci 63:167-171. https://doi.org/10.2478/v10222-012-0080-6

19. Meda A, Lamien CE, Romito M et al (2005) Determination of the total phenolic, flavonoid and proline contents in Burkina Fasan honey, as well as their radical scavenging activity. Food Chem 91:571-577. https://doi.org/10.1016/j.foodchem.2004.10.006

20. Lee J, Durst RW, Wrolstad RE (2005) Determination of total monomeric anthocyanin pigment content of fruit juices, beverages, natural colorants, and wines by the $\mathrm{pH}$ differential method: collaborative study. J AOAC Int 88:1269-1278

21 Hullatti K, Telagari M (2015) In-vitro $\alpha$-amylase and $\alpha$-glucosidase inhibitory activity of Adiantum caudatum Linn. and Celosia argentea Linn. extracts and fractions. Indian J Pharmacol 47:425. https://doi.org/10.4103/0253-7613.161270

22. Gąstoł M, Krośniak M, Derwisz M, Dobrowolska-Iwanek J (2013) Cornelian cherry (Cornus mas L.) juice as a potential source of biological compounds. J Med Food 16:728-732. https://doi. org/10.1089/jmf.2012.0248

23. De Biaggi M, Donno D, Mellano MG et al (2018) Cornus mas (L.) fruit as a potential source of natural health-promoting compounds: physico-chemical characterisation of bioactive components. Plant Foods Hum Nutr 73:89-94. https://doi.org/10.1007/ s11130-018-0663-4

24. Milenkovic-Andjelkovic A, Andjelkovic M, Radovanovic A et al (2015) Phenol composition, DPPH radical scavenging and antimicrobial activity of cornelian cherry (Cornus mas) fruit and leaf extracts. Hem Ind 69:331-337. https://doi.org/10.2298/HEMIN D140216046M

25. Moldovan B, Filip A, Clichici S et al (2016) Antioxidant activity of cornelian cherry (Cornus mas L.) fruits extract and the in vivo evaluation of its anti-inflammatory effects. J Funct Foods 26:77-87. https://doi.org/10.1016/j.jff.2016.07.004

26. Kucharska AZ, Szumny A, Sokól-Letowska A et al (2015) Iridoids and anthocyanins in cornelian cherry (Cornus mas L.) cultivars. J Food Compos Anal 40:95-102. https://doi.org/10.1016/j. jfca.2014.12.016
27. Sozański T, Kucharska AZ, Szumny A et al (2014) The protective effect of the Cornus mas fruits (cornelian cherry) on hypertriglyceridemia and atherosclerosis through PPAR $\alpha$ activation in hypercholesterolemic rabbits. Phytomedicine 21:1774-1784. https ://doi.org/10.1016/J.PHYMED.2014.09.005

28. Craik CS, Page MJ, Madison EL (2011) Proteases as therapeutics. Biochem J 435:1-16. https://doi.org/10.1042/BJ20100965

29. Volpato GT, Calderon IMP, Sinzato S et al (2011) Effect of Morus nigra aqueous extract treatment on the maternal-fetal outcome, oxidative stress status and lipid profile of streptozotocininduced diabetic rats. J Ethnopharmacol 138:691-696. https://doi. org/10.1016/j.jep.2011.09.044

30. Furman BL, Candasamy M, Bhattamisra SK, Veettil SK (2020) Reduction of blood glucose by plant extracts and their use in the treatment of diabetes mellitus; discrepancies in effectiveness between animal and human studies. J Ethnopharmacol. https:// doi.org/10.1016/j.jep.2019.112264

31. Tahmasebi L, Zakerkish M, Golfakhrabadi F, Namjoyan F (2019) Randomised clinical trial of Berberis vulgaris root extract on glycemic and lipid parameters in type 2 diabetes mellitus patients. Eur J Integr Med 32:100998. https://doi.org/10.1016/j.eujim .2019 .100998

32. Soltani R, Gorji A, Asgary S et al (2015) Evaluation of the effects of Cornus mas L. fruit extract on glycemic control and insulin level in type 2 diabetic adult patients: a randomized double-blind placebo-controlled clinical trial. Evid Based Complement Altern Med. https://doi.org/10.1155/2015/740954

33. You Q, Chen F, Wang X et al (2012) Anti-diabetic activities of phenolic compounds in muscadine against alpha-glucosidase and pancreatic lipase. LWT Food Sci Technol 46:164-168. https://doi. org/10.1016/j.1wt.2011.10.011

34. Proença C, Freitas M, Ribeiro D et al (2017) $\alpha$-Glucosidase inhibition by flavonoids: an in vitro and in silico structure-activity relationship study. J Enzyme Inhib Med Chem 32:1216-1228. https://doi.org/10.1080/14756366.2017.1368503

35. David L, Danciu V, Moldovan B, Filip A (2019) Effects of in vitro gastrointestinal digestion on the antioxidant capacity and anthocyanin content of cornelian cherry fruit extract. Antioxidants 8:114. https://doi.org/10.3390/antiox8050114

Publisher's Note Springer Nature remains neutral with regard to jurisdictional claims in published maps and institutional affiliations. 